RESEARCH ARTICLE

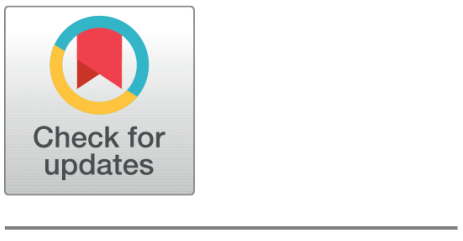

OPEN ACCESS

Received: 12.01.2021

Accepted: 27.02.2021

Published: 02.03 .2021

Citation: Xu W, Kumar IR, Srinivasan TM (2021) Effects of Yama and Niyama on body energy systems: Evidence from Electro Photonic Imaging - A randomised controlled trial. Indian Journal of Science and Technology 14(7): 610-617. https://doi.org/ 10.17485/IJST/v14i7.66

* Corresponding author.

Tel: +919380403747

estherxu@hotmail.com

Funding: None

Competing Interests: None

Copyright: (c) $2021 \mathrm{Xu}$ et al. This is an open access article distributed under the terms of the Creative Commons Attribution License, which permits unrestricted use, distribution, and reproduction in any medium, provided the original author and source are credited.

Published By Indian Society for Education and Environment (iSee)

ISSN

Print: 0974-6846

Electronic: 0974-5645

\section{Effects of Yama and Niyama on body energy systems: Evidence from Electro Photonic Imaging - A randomised controlled trial}

\author{
Wen $\mathrm{Xu}^{\mathbf{1}}{ }^{\text {}}$, Itagi R Kumar ${ }^{1}$, Thaiyar M Srinivasan ${ }^{1}$ \\ 1 Division of Yoga and Physical Sciences, S-VYASA Deemed-to-be-University, No. 19, Eknath \\ Bhavan, Gavipuram Circle, Kempegowdanagar, Bengaluru, 560019, Karnataka, India. Tel.: +91 \\ 9380403747
}

\section{Abstract}

Background/Objective: The purpose of this study was to evaluate the impact of yogic practices of Yama and Niyama on changes in energy in the body and organs related to emotions in young adults. Methods/Statistical analysis:The present study was a randomised control trial. A total of 100 young healthy adults with 71 males and 29 females randomly allocated to study the effects of Yama and Niyama for 12 weeks. The control group was arranged to take a regular course for 45 minutes which was the same time duration as the YamaNiyama intervention. Assessments included were energy and health status in the person, and energy and entropy levels in the five major organs related to emotions using Bio-Well device. Findings: The optimal energy stability was observed in Yama-Niyama group after the intervention compared to the control group. Energy level variables of the human energy field, health status, energy reserve, heart, liver, spleen, lung and kidney values in Yama-Niyama group showed a statistical difference $(p<0.001)$ after the intervention compared to the control group. The entropy level of five emotion-related organs for betweengroup comparison showed no significant differences after the intervention. In the within-group comparison, the results of Yama-Niyama group showed a significant reduction in physical energy level from hyperactive to normal range after the intervention compared to baseline, whereas the control group showed a significant decrease and out of normal range. The optimal energy stability in Yama-Niyama group indicating an improvement in physical function. Novelty : The current study provides preliminary evidence that Yama and Niyama intervention improved the regulation of subtle energy in the body and might balance vital energy in meridians to further promote physiological wellbeing.

Keywords: Yama; Niyama; Yoga ethics; energy; emotional organs; BioWell 


\section{Introduction}

Yoga is a system of the scientific method for self-realization which originated in ancient times in India. In the modern era, the science of yoga has investigated dimensions of anatomy, physiology and psychology. Publications on the therapeutic benefits of yoga have significantly increased since $2009^{(1)}$. The authors noted that primary yoga interventions for mental health, cardiovascular and respiratory diseases were the largest number of cases investigated. A substantial number of studies reveal positive effects on psychophysiological health through these practices ${ }^{(2)}$. Interestingly, yoga practices have also demonstrated improved regulation of the entire organism by balancing acupuncture meridian energy, which links yoga and Traditional Chinese medicine (TCM) $)^{(3,4)}$.

In yoga, prana is described as subtle energy (life force) flowing through nadis (energy channels) which is the equivalent of qi (vital energy) in TCM meridians ${ }^{(5)}$. The meridian theory is one of the basic principles of TCM and states that qi flows through channel systems (meridians) connected to internal organs and functions ${ }^{(6)}$. Illness is ascribed to imbalance or blockage of qi in different meridians ${ }^{(7)}$. Prana cannot be measured yet, but Electro Photonic Image (EPI) measures are generally recognized to reflect the biological field and assess the subtle energy changes in meridians in the human body, which is consistent with TCM approaches ${ }^{(8,9)}$.Several studies revealed meditation ${ }^{(10,11)}$ and integrated yoga practices ${ }^{(12-14)}$ significantly improved the overall energy of communication, reduced the stress level, and tends to decrease the disorderliness of energy flow in the organ systems.

Energy is the resource of life that sustains humans for physical and emotional activity. Modern science and the ancient teachings of Chinese medicine state that matter is only a vibration of energy. In ancient India, the seers declared that energy is a vibration of thoughts ${ }^{(15)}$. In yoga philosophy, the mind is seen as the source of energy, the mind being the brain, feelings, and perceptions of all living cells in the body, keeping the human body alert or depressed. Thus, the mind is the chief governor of the body; hence we should consider the nutritive potency of the psychological menus that we daily serve the mind. According to TCM, seven emotions interact with five major organs (heart, lung, liver, spleen, kidney). Huangdi Neijing further states that mind-body health is associated with the balanced movement of $\mathrm{qi}^{(16)}$. Thus, yoga practices such as asana, pranayama and meditation are said to remove blockages, enliven prana and promote its smooth flow through the subtle channels, which ameliorates physical, mental, or emotional discomfort ${ }^{(17)}$.

The ethical principles of Yama (five proscriptive moralities) and Niyama (five prescriptive rules) are enumerated in Patañjalis Yoga Sütrās they are universal rules of ethical lifestyle. Yamas are those principles of wrong behaviour, which we should shun. The components of Yamas are non-violence or harmlessness (ahimsa), truthfulness (satya), non-stealing (asteya), continence (brahmacharya) and non-covetousness (aparigraha). Niyamas are those principles of right behaviour, which should be embraced. The Niyamas are purity of body and mind (sauca), contentment in all circumstances (santosa), austerity or selfdiscipline (tapas), introspective study of the scriptures (svadhyaya) and surrender to God (Isvarapranidhana). These ethical insights are not only simple in theory but also help in developing the mind and body ${ }^{(18)}$. Although yoga ethics embodied tremendous value for balancing the body, mind, and spirit, it has been neglected in the yoga classes and out of the yoga mat as well $^{(19)}$, and has remained unknown in its impact on the energy field of a person practicing. Hence, we tested the hypothesis that the practice of Yama and Niyama potentially impacts the overall energy level in the human body, as well as the health and entropy status of the five major organs related to emotions.

\section{Materials and Methods}

As per previous study ${ }^{(12)}$ and considering alpha (0.05), power (0.95), effect size (0.84), the total sample size for each group was found to be 38 by using $G^{\star}$ Power software. Calculating $25 \%(38+25 \%)$ attrition, the sample size was 47.5 . One hundred participants who were all college students were randomly allotted to two groups: control group $(n=50$, male $=39$, female $=11$, age, $\mathrm{M} \pm \mathrm{SD}=19.62 \pm 1.23$ ) and Yama and Niyama $(\mathrm{YN})$ group $(\mathrm{n}=50$, male $=32$, female $=18$, age, $\mathrm{M} \pm \mathrm{SD}=19.28 \pm 1.16)$. The random allocation sequence was generated (using the website www.random.org) which was concealed in sealed envelopes to prevent selection bias, until the allocation. Demographic information sheets were distributed to find out the age, educational attainment, health status and past yoga experience in both groups. Daily record sheets were distributed to YN group which offer a way to understand their practice experiences. The inclusion criteria were: age between 18-26 years, without yoga experience, and understanding the English language. The exclusion criteria were: with yoga experience, missing fingers (all fingers are required for Bio-Well measurements), and having no self-reported physical or mental disorders. This research protocol was approved by the institutional ethics committee and informed consent was obtained from all the participants. 


\subsection{Intervention}

This study was implemented for 12 weeks, 6 days per week, 45 minutes in each session. The YN group intervention included Yama and Niyama lectures, Japa writing, introspection, and counseling, as presented in Appendix 1. The control group followed one of their college classes for the same duration of time as the intervention group; attendance was maintained by their course teachers.

\subsection{Assessments}

The Electro Photonic Imaging (EPI) measurement instrument is called Bio-Well through which it is possible to measure the subtle energy reserve in a person. The EPI technology is based on the concept of quantum biophysics ${ }^{(20)}$. This method for investigating human functional energy states is based on the stimulation of photon and electron emissions from the surface of the skin whilst transmitting short electrical pulses ${ }^{(8)}$. Bio-Well device was developed by Dr. Korotkov and his team and is a reliable, non-invasive tool and verified in many clinical case studies over the last 20 years. It has high accuracy and repeatability as reported through many studies ${ }^{(21)}$. The principle is based on the connection of areas on finger pads with different organs as well as systems of the body according to the science of Chinese energy meridians ${ }^{(8)}$. EPI data readings (Bio-grams) include energy, stress, and entropy evaluations obtained from 10 images of fingers of both the hands and is captured by a CCD camera system. Numbers indicate the level of energy (in Joules). The parameters of EPI measurements are as follow:

1. Human Energy Field (HEF) reflects the physical and emotional state of an individual and has a range of 40-70J indicating normal energy.

2. Health Status (HS) is the general health index analysis of the functional state of the human body and reflects energy distribution for different organs and systems; the optimal health condition is in the range of -0.6 to +1 .

3. Energy Reserve (ER) is the energy status of the human body obtained by calculating the energy parameter of a particular organ. The optimal level is from $20 \%$ to $60 \%$.

4. The energy level of five major emotional-related organs (heart, lung, liver, spleen, kidney); a range of 4-6J is considered a normal level.

5. Entropy parameter measures disorderliness of energy in the five major emotional related organs, the normal range is from 1 to 2 .

Two assessments (baseline and after intervention) were conducted at the same time (8:30 am to 11:30 am) of the day, and in the same place with good ventilation. Participants were asked to report to the bioenergy data centre with an empty stomach as well as with an empty bladder and bowel. Before the assessments, the Bio-Well equipment should be grounded properly and at a distance of more than $50 \mathrm{~cm}$ from the computer system. Appropriate calibration of the Bio-Well was carried out before capture the EPI diagrams from the 10 fingers. After each recording, the electrode's glass surface was cleaned with soft tissue.

\subsection{Data analysis}

Data were analysed using Statistical Packages for Social Sciences (SPSS) version 23. Repeated Measures Analysis of Variance (RM-ANOVA) with the pre-scores as a covariate was used for energy level analysis (Table 2). Repeated Measures ANOVA was used for entropy level analysis (Table 3 ). A level of $\mathrm{p}<0.05$ was considered statistically significant.

\section{Results}

Out of 100 participants, data was gathered from a total of 85 for analysis (excluding 15 participants who did not have the required at least $80 \%$ attendance for the classes). No statistically significant differences were seen between the two groups in demographic factors (Table 1).

Table 2 shows the overall energy level in the body and its five emotion-related organs. There was a statistically significant difference at the time points (baseline, after intervention), for HEF score, $\mathrm{F}(1,83)=109.21, p<0.001$; for HS score, $\mathrm{F}(1,83)=211.16$, $\mathrm{p}<0.001$; for ER score, $\mathrm{F}(1,83)=186.88, \mathrm{p}<0.001$; for heart score, $\mathrm{F}(1,83)=101.33, \mathrm{p}<0.001$; for liver score, $\mathrm{F}(1,83)=70.55$, $\mathrm{p}<0.001$; for spleen score, $\mathrm{F}(1,83)=40.17, \mathrm{p}<0.001$; for lung score, $\mathrm{F}(1,83)=101.37, \mathrm{p}<0.001$; and for kidney score, $\mathrm{F}(1,83)=73.81$, $\mathrm{p}<0.001$. There was a significant difference in group and time interaction, for HEF score, $\mathrm{F}(1,83)=31.67, \mathrm{p}<0.001$; for HS score, $\mathrm{F}(1,83)=34.94, \mathrm{p}<0.001$; for $\mathrm{ER}$ score, $\mathrm{F}(1,83)=29.51, \mathrm{p}<0.001$; for heart score, $\mathrm{F}(1,83)=24.11, \mathrm{p}<0.001$; for liver score, $\mathrm{F}(1,83)=21.86, \mathrm{p}<0.001$; for spleen score, $\mathrm{F}(1,83)=22.81$, $\mathrm{p}<0.001$; for lung score, $\mathrm{F}(1,83)=22.51, \mathrm{p}<0.001$; and for kidney score, $\mathrm{F}(1,83)=23.53, \mathrm{p}<0.001$. 
Table 1. Baseline characteristics

\begin{tabular}{|c|c|c|c|}
\hline Characteristics & YN group & Control group & Difference \\
\hline Age $(\mathrm{M} \pm \mathrm{SD})$ & $19.28 \pm 1.16$ & $19.62 \pm 1.23$ & NS \\
\hline \multicolumn{4}{|l|}{ Gender } \\
\hline Male & 32 & 39 & \multirow{2}{*}{ NS } \\
\hline Female & 18 & 11 & \\
\hline \multicolumn{4}{|l|}{ Marital status } \\
\hline Unmarried & 50 & 50 & NS \\
\hline \multicolumn{4}{|l|}{ Educational status } \\
\hline High school grad. & 50 & 50 & NS \\
\hline \multicolumn{4}{|l|}{ Health Status } \\
\hline Good to excellent & 50 & 50 & NS \\
\hline \multicolumn{4}{|l|}{ Yoga experience } \\
\hline No & 50 & 50 & NS \\
\hline
\end{tabular}

Note: NS = Not Significant, YN = Yama and Niyama, $\mathrm{M}=$ Mean, $\mathrm{SD}=$ Standard Deviation

Table 2. Comparison between/within Yama-Niyama and control groups for energy level at baseline and after intervention

\begin{tabular}{|c|c|c|c|c|c|}
\hline variables & Group & Baseline & After intervention & $\mathrm{F}(\mathrm{p})$ values (Factor) & $\mathrm{F}(\mathrm{p})$ values $($ Factor $\times$ level $)$ \\
\hline \multirow{2}{*}{$\mathrm{HEF}$} & $\mathrm{YN}$ & $54.31 \pm 8.35^{\mathrm{bb}}$ & $47.89 \pm 6.58^{* * *} \mathrm{bbb}$ & \multirow{2}{*}{$109.27(<0.001)$} & \multirow{2}{*}{$31.67(<0.001)$} \\
\hline & Control & $60.57 \pm 10.75$ & $39.15 \pm 7.16^{* * *}$ & & \\
\hline \multirow{2}{*}{ HS } & YN & $0.01 \pm 0.35^{\mathrm{b}}$ & $-0.40 \pm 0.25^{* * *} \mathrm{bbb}$ & \multirow{2}{*}{$211.16(<0.001)$} & \multirow{2}{*}{$34.94(<0.001)$} \\
\hline & Control & $0.16 \pm 0.29$ & $-0.80 \pm 0.37^{* * *}$ & & \\
\hline \multirow{2}{*}{ ER } & YN & $79.18 \pm 27.49$ & $50.68 \pm 23.36^{* * *} \mathrm{bbb}$ & \multirow{2}{*}{$188.88(<0.001)$} & \multirow{2}{*}{$29.51(<0.001)$} \\
\hline & Control & $87.36 \pm 16.50$ & $21.27 \pm 24.54^{* * *}$ & & \\
\hline \multirow{2}{*}{ Heart } & $\mathrm{YN}$ & $4.77 \pm 0.86^{\mathrm{b}}$ & $3.99 \pm 0.73^{* * \star} \mathrm{bbb}$ & \multirow{2}{*}{$101.33(<0.001)$} & \multirow{2}{*}{$24.11(<0.001)$} \\
\hline & Control & $5.31 \pm 1.25$ & $3.03 \pm 0.87^{* * *}$ & & \\
\hline \multirow{2}{*}{ Liver } & $\mathrm{YN}$ & $5.60 \pm 1.71$ & $4.79 \pm 1.12^{*} \mathrm{bbb}$ & \multirow{2}{*}{$70.55(<0.001)$} & \multirow{2}{*}{$21.86(<0.001)$} \\
\hline & Control & $6.28 \pm 1.84$ & $3.45 \pm 1.20^{* * *}$ & & \\
\hline \multirow{2}{*}{ Spleen } & YN & $4.30 \pm 1.01^{\mathrm{bb}}$ & $5.17 \pm 1.39^{\mathrm{bbb}}$ & \multirow{2}{*}{$40.17(<0.001)$} & \multirow{2}{*}{$22.81(<0.001)$} \\
\hline & Control & $4.03 \pm 0.80$ & $3.29 \pm 0.89^{* * *}$ & & \\
\hline \multirow{2}{*}{ Lung } & YN & $5.28 \pm 1.23^{b}$ & $4.38 \pm 0.91^{* * *} \mathrm{bbb}$ & \multirow{2}{*}{$101.37(<0.001)$} & \multirow{2}{*}{$22.51(<0.001)$} \\
\hline & Control & $5.91 \pm 1.27$ & $3.39 \pm 0.89^{* * *}$ & & \\
\hline \multirow{2}{*}{ Kidney } & $\mathrm{YN}$ & $5.13 \pm 1.17$ & $4.45 \pm 0.83^{*} \mathrm{bbb}$ & \multirow{2}{*}{$101.37(<0.001)$} & \multirow{2}{*}{$22.51(<0.001)$} \\
\hline & Control & $5.91 \pm 1.63$ & $3.27 \pm 0.99^{* * *}$ & & \\
\hline
\end{tabular}

Note: ${ }^{*} \mathrm{p}<0.05,{ }^{* *} \mathrm{p}<0.01,{ }^{* * *} \mathrm{p}<0.001$ within group comparison ${ }^{\mathrm{b}} \mathrm{p}<0.05,{ }^{b b} \mathrm{p}<0.01,{ }^{b b b} \mathrm{p}<0.001$ between group comparison Repeated Measures ANOVA after Bonferroni's adjustment

For between-group comparison, there was a significant difference in HEF score at the time point of baseline $(\mathrm{p}=0.004)$ and after the intervention $(\mathrm{p}<0.001)$. There was a significant difference between groups (YN \& Control) on post-HEF score (after intervention) after controlling baseline HEF score, $\mathrm{F}(1,82)=28.46, \mathrm{p}<0.001$. There was a significant difference in HS score at the baseline $(\mathrm{p}=0.033)$ and after the intervention $(\mathrm{p}<0.001)$. There was a significant difference between groups (YN \& Control) on post-HS score after controlling baseline HS score, $\mathrm{F}(1,82)=34.14, \mathrm{p}<0.001$. There was a significant difference in ER score after intervention $(\mathrm{p}<0.001)$. There was a significant difference in heart score at the baseline $(\mathrm{p}=0.026)$ and after intervention $(\mathrm{p}<0.001)$. There was a significant difference between groups (YN \& Control) on post-heart score after controlling baseline heart score, $F(1,82)=26.39, p<0.001$. There was a significant difference in liver score after intervention $(\mathrm{p}<0.001)$. There was a significant difference in spleen score at the baseline $(\mathrm{p}=0.002)$ and after intervention $(\mathrm{p}<0.001)$. There was a significant difference between groups (YN \& Control) on post-spleen score after controlling baseline spleen score, $F(1,82)=12.36, p<0.001$. There was a significant difference in lung score at the baseline $(\mathrm{p}=0.024)$ and after intervention $(\mathrm{p}<0.001)$. There was a significant difference between groups (YN \& Control) on post-lung score after controlling baseline lung score, $F(1,82)=23.13, p<0.001$. There was a significant difference in kidney score after intervention $(\mathrm{p}<0.001)$. 
The results in Yama-Niyama group showed a significant decrease in HEF ( $p<0.001)$, HS ( $<<0.001)$, ER ( $<<0.001)$, heart $(\mathrm{p}<0.001)$, lung $(\mathrm{p}<0.001)$, liver $(\mathrm{p}=0.012)$ and kidney $(\mathrm{p}=0.012)$ score. There was a significant decrease $(\mathrm{p}<0.001)$ in all variables observed in the control group.

Table 3 shows the entropy level of five emotion-related organs. There was a statistical significant difference at the time points (baseline, after intervention), for heart score, $\mathrm{F}(1,83)=15.83, \mathrm{p}<0.001$; for liver score, $\mathrm{F}(1,83)=17.28$, $\mathrm{p}<0.001$; for spleen score, $\mathrm{F}(1,83)=34.24, \mathrm{p}<0.001$; for lung score, $\mathrm{F}(1,83)=48.66, \mathrm{p}<0.001$; and for kidney score, $\mathrm{F}(1,83)=51.79$, $\mathrm{p}<0.001$. There was no significant difference in group and time interaction.

There was no significant difference between groups for the mean entropy level. For within-group comparison, the YN group showed statistically significant decrease in the entropy score of heart $(\mathrm{p}=0.014)$, liver $(\mathrm{p}=0.002)$, spleen $(\mathrm{p}=0.002)$, lung $(\mathrm{p}<0.001)$ and kidney $(\mathrm{p}<0.001)$; the control group also showed significant decrease in the entropy score of heart $(\mathrm{p}=0.002)$, liver $(\mathrm{p}=0.010)$, spleen $(\mathrm{p}<0.001)$, lung $(\mathrm{p}<0.001)$ and kidney $(\mathrm{p}<0.001)$.

Table 3. Comparison between/within Yama-Niyama and control groups for entropy level at baseline and after intervention

\begin{tabular}{|c|c|c|c|c|c|}
\hline variables & Group & Baseline & After intervention & $\mathrm{F}(\mathrm{p})$ values (Factor) & $\mathrm{F}(\mathrm{p})$ values $($ Factor $\times$ level $)$ \\
\hline \multirow{2}{*}{ Heart } & YN & $2.51 \pm 0.33$ & $2.31 \pm 0.20^{*}$ & \multirow{2}{*}{$15.83(<0.001)$} & \multirow{2}{*}{$0.10(0.750)$} \\
\hline & Control & $2.60 \pm 0.34$ & $2.37 \pm 0.49^{* *}$ & & \\
\hline \multirow{2}{*}{ Liver } & $\mathrm{YN}$ & $2.50 \pm 0.46$ & $2.19 \pm 0.25^{* *}$ & \multirow{2}{*}{$17.28(<0.001)$} & \multirow{2}{*}{$0.31(0.576)$} \\
\hline & Control & $2.56 \pm 0.46$ & $2.32 \pm 0.40^{*}$ & & \\
\hline \multirow{2}{*}{ Spleen } & YN & $2.36 \pm 0.31$ & $2.04 \pm 0.17^{* *}$ & \multirow{2}{*}{$34.24(<0.001)$} & \multirow{2}{*}{$1.51(0.223)$} \\
\hline & Control & $2.63 \pm 0.72$ & $2.15 \pm 0.33^{\star * *}$ & & \\
\hline \multirow{2}{*}{ Lung } & YN & $2.41 \pm 0.29$ & $2.21 \pm 0.17^{* * *}$ & \multirow{2}{*}{$48.66(<0.001)$} & \multirow{2}{*}{$1.04(0.312)$} \\
\hline & Control & $2.47 \pm 0.26$ & $2.20 \pm 0.22^{* * *}$ & & \\
\hline \multirow{2}{*}{ Kidney } & YN & $2.47 \pm 0.24$ & $2.25 \pm 0.17^{* * \star}$ & \multirow{2}{*}{$51.79(<0.001)$} & \multirow{2}{*}{$2.12(0.149)$} \\
\hline & Control & $2.58 \pm 0.31$ & $2.24 \pm 0.29^{* * *}$ & & \\
\hline
\end{tabular}

Note: ${ }^{*} \mathrm{p}<0.05,{ }^{* *} \mathrm{p}<0.01,{ }^{* * *} \mathrm{p}<0.001$ within group comparison ${ }^{\mathrm{b}} \mathrm{p}<0.05,{ }^{b \mathrm{~b}} \mathrm{p}<0.01,{ }^{\text {bbb }} \mathrm{p}<0.001$ between group comparison Repeated Measures ANOVA after Bonferroni's adjustment

\section{Discussion}

In summary, the current study is the first randomised control trial of Yama and Niyama (YN) intervention to analyse the subtle energy in the human body. The results of the experiment have shown that after 12 weeks of regular YN practices, statistically significant differences were observed in the physiological energy levels in the body compared to the control group. In the YN group, all the variables are significantly decreased after the intervention and all in optimal energy level, regardless of the changes in external conditions (e.g., low temperature, academic exams). The energy level of the five major emotion-related organs showed optimal homeostasis. Data obtained from Bio-Well found that the values of physiological energy parameters were very stable in the YN group. These data indicate improvement in physical health, optimization of the five major emotionrelated organs, and harmony between the specific emotions and related corresponding organs. The observation showed the variables of the control group are all below normal range, which indicates lower homeostasis levels in the body and its emotionrelated organs.

Furthermore, the findings of entropy level at baseline and after intervention have clearly shown that practice of ethical disciplines of Yama and Niyama over a duration of time not only reduced the disarray in the body energy system but also improved regulation of the emotions in a profound way. The improvements in emotions were also noticed in the personal reports the participants shared with the researcher at the end of the program; these are not shared in this report. The entropy level showed a significant decrease in both groups after intervention compared to baseline. However, it is seen that at the second measurement, the ER value in the control group was below the normal range. The above result related to lowered entropy is possible when the energy itself is largely decreased in the body ${ }^{(21)}$.

Numerous studies have shown yoga for mind-body development and as an effective self-care skill for emotional regulation ${ }^{(22-24)}$. The researchers suggest that the mechanism behind these observations may be ascribed to yoga practices that affect the autonomic nervous system ${ }^{(25)}$, which leads to balance and regulate the functioning of sympathetic-parasympathetic nervous system; therefore, the abnormal flow of bioenergy may further be reduced and corrected. This argument might be supported through improved optimum size and uniformity of the bio-gram glow area after yoga practices ${ }^{(26)}$. Another study reported the parameter for detecting stress reaction, namely alpha-amylase decreased with a concomitant increase in glow area 
homogeneity in EPI images ${ }^{(27)}$. Yama and Niyama practices may share similar mechanisms of balancing the autonomic nervous system.

Traditional Chinese Medicine views seven emotions are closely related to corresponding five primary organs: joy links with the heart, anger with the liver, pensiveness with the spleen, worry and sadness with the lung, and fear and shock with the kidney ${ }^{(28)}$. In other words, the influence of excessive emotions consumes energy and leads to damage of the related visceral organs, eventually causing health problems. For example, excessive anger reduces liver energy; further, the flow of qi rises to the head resulting in headache, high blood pressure, and other symptoms. Recent studies in neurosciences have demonstrated emotions mapped on bodily locations ${ }^{(29,30)}$, especially linking points on the body that are involved in many kinds of cognitive and emotional functions. Surprisingly, it is also observed that the heart reflected all emotions, which is in line with the principles of $\mathrm{TCM}^{(16)}$. This reliable evidence from Eastern and Western studies shows that the human mind is strongly embodied. The results of five major emotion-related organs agree with the previous findings that emotions affect our physiologic functions.

The benefits of components of yoga including asana, pranayama and meditation for physical and psychological health have been examined in a wide array of studies ${ }^{(1,2)}$. In the present study, the physiological energy parameters of HER, ER, HS, and the energy in the five major emotion-related organs also showed improved levels which suggests that YN intervention improved energy regulation in the body. It may be attributed to the reduced fluctuation of emotions resulting in improved life force circulation and harmony in physical functions, promoting positive health. This research demonstrates that the practice of ethics of yoga improves physiological energy changes which are consistent with the previous findings ${ }^{(10,12,14)}$.

The present study provides evidence that regular daily practice of Yama and Niyama can aid homeostasis energy to stay within a stable range, better coping with the changes in environmental conditions, and keeping the mind and body in a more robust harmony. Furthermore, the practice of the Yama and Niyama techniques heightens awareness and cognitive ability, provides the basis to regulate emotions, and removes blockages of vital energy in meridians.

\section{Limitations and Future Implications}

First, a single assessment tool used here that does not provide an examination of the psychological mechanisms was a limitation. Second, it is not possible to maintain constant environmental conditions of average temperature $\left(20 \pm 5^{\circ} \mathrm{C}\right)$ and humidity $(70 \pm 20 \%)$, which may influence the emission pattern of Electro Photonic Imaging. Future studies should consider different age groups, health problems, and various assessment tools for further understanding the relationship between emotions and bodily changes, especially the subtle energy changes in the brain. In addition, combining Yama and Niyama with other limbs of yoga in practices might bring more benefits to overall health. It is noted that Yama and Niyama intervention may be added to complementary and alternative medicine practices in promoting physical and mental health.

\section{Conclusions}

In summary, the present findings demonstrated Yama-Niyama intervention provides stability of physiological energy in the body. Outcomes of the study suggest that ethical disciplines of yoga can be applied to regulate subtle energy.

\section{Acknowledgements}

We would like to thank the support from Yogoda Satsanga Society and Yogoda Satsanga Mahavidyalaya College, Ranchi, India.

\begin{tabular}{|c|c|c|c|}
\hline \multicolumn{4}{|c|}{ Appendix 1: Yama and Niyama intervention for 12 weeks } \\
\hline Name of the practice & Duration & Contents & \\
\hline \multirow{5}{*}{ Yama and niyama lecture } & \multirow{5}{*}{$15 \mathrm{~min}$} & $\begin{array}{l}\text { 1. Explain the concept of each ethical discil } \\
\text { example: }\end{array}$ & ine and how to practice in daily life, for \\
\hline & & Yamas & Niyamas \\
\hline & & $\begin{array}{l}\text { Ahimsa: not to hurt any creatures: human } \\
\text { beings, animals, plants }\end{array}$ & $\begin{array}{l}\text { Sauca: purify the physical, mental and } \\
\text { environment. }\end{array}$ \\
\hline & & $\begin{array}{l}\text { Satya: speak and observe the truth in } \\
\text { thoughts, words and actions }\end{array}$ & $\begin{array}{l}\text { Santosa: simple living, high thinking, } \\
\text { be still within, be non-attached }\end{array}$ \\
\hline & & $\begin{array}{l}\text { Asteya: simplify life by eliminating all non- } \\
\text { essential things and activities }\end{array}$ & $\begin{array}{l}\text { Tapas: austerity of the body, speech, } \\
\text { mind }\end{array}$ \\
\hline
\end{tabular}

Continued on next page 


\begin{tabular}{|c|c|c|}
\hline \multicolumn{3}{|c|}{ Table 4 continued } \\
\hline & & $\begin{array}{l}\text { Svadhyaya: reading scriptures with } \\
\text { understanding its meaning and assimi- } \\
\text { lating it into life }\end{array}$ \\
\hline & & $\begin{array}{ll}\text { Aparigraha: purify the heart of envy and } & \text { Isvarapranidhana: cultivate an } \\
\text { jealousy, the right motivation and corre- } & \text { increased trust, faith, understand- } \\
\text { sponding effort } & \text { ing and devotion in God }\end{array}$ \\
\hline & & $\begin{array}{l}\text { 2. Through the topic of 'Ridding the consciousness of worry' and 'The law of success', } \\
\text { discuss how it manifests the Yama and Niyama disciplines. }\end{array}$ \\
\hline \multirow[t]{3}{*}{ Japa writing } & \multirow[t]{3}{*}{$20 \mathrm{~min}$} & \multirow{3}{*}{ 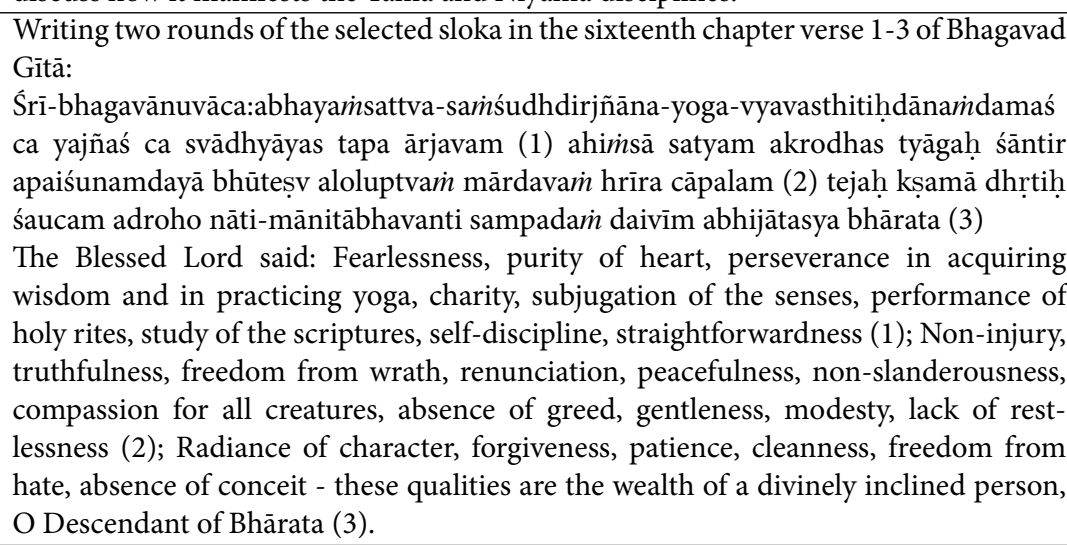 } \\
\hline & & \\
\hline & & \\
\hline Introspection & $5 \mathrm{~min}$ & $\begin{array}{l}\text { According to each YN lecture theme, first mentally review the different circumstances } \\
\text { observe the negative quality or behaviour that violates Yama and Niyama, then resolve } \\
\text { how one is going to change one's behaviour; identifying and concentration on the } \\
\text { positive quality or behaviour one is going to adopt, and lastly affirm the positive quality } \\
\text { to instead of the negative trait, going forward into to a conscious reaffirmation and } \\
\text { pray: "Make me a master of Yama and Niyama". }\end{array}$ \\
\hline Counselling & $5 \mathrm{~min}$ & Clearing of the questions/doubts in the class or related to life problems. \\
\hline
\end{tabular}

\section{References}

1) Jeter PE, Slutsky J, Singh N, Khalsa SBS. Yoga as a Therapeutic Intervention: A Bibliometric Analysis of Published Research Studies from 1967 to 2013. The Journal of Alternative and Complementary Medicine. 2015;21(10):586-592. Available from: https://dx.doi.org/10.1089/acm.2015.0057.

2) Field T. Yoga research review. Complementary Therapies in Clinical Practice. 2016;24:145-161. Available from: https://doi.org/10.1016/j.ctcp.2016.06.005.

3) Hankey A, Nagendra HR, Nagilla N. Effects of yoga practice on acumeridian energies: Variance reduction implies benefits for regulation. International Journal of Yoga. 2013;6(1). Available from: https://dx.doi.org/10.4103/0973-6131.105948.

4) Sharma B, Hankey A, lBaburajan Meenakshy K, Nagendra HR, Nagilla N. Can yoga practices benefit health by improving organism regulation? Evidence from electrodermal measures of acupuncture meridians. International Journal of Yoga. 2014;7(1):-. Available from: https://dx.doi.org/10.4103/0973-6131. 123477.

5) Srinivasan T. Prana and electrons in health and beyond. International Journal of Yoga. 2014;7(1):1-3. Available from: https://doi.org/10.4103/0973-6131. 123469.

6) Longhurst JC. Defining Meridians: A Modern Basis of Understanding. Journal of Acupuncture and Meridian Studies. 2010;3(2):67-74. Available from: https://dx.doi.org/10.1016/s2005-2901(10)60014-3.

7) Nestler G. Traditional Chinese medicine. Medical Clinics of North America. 2002;86:63-73. Available from: https://dx.doi.org/10.1016/s0025-7125(03) 00072-5.

8) Korotkov KG. Electrophotonic Analysis: Energy Fields Electrophotonic Analysis in Humans and Nature. Create Space Independent Publishing Platform. 2014.

9) Narayanan CR, Korotkov K, Srinivasan TM. Bioenergy and its implication for yoga therapy. International Journal of Yoga. 2018;11(2). Available from: https://dx.doi.org/10.4103/ijoy.ijoy_54_17.

10) Deo G, Itagi RK, Thaiyar MS, Kuldeep K. Effect of anapanasati meditation technique through electrophotonic imaging parameters: A pilot study. International Journal of Yoga. 2015;8(2). Available from: https://dx.doi.org/10.4103/0973-6131.158474.

11) Kushwah KK, Srinivasan TM, Nagendra HR, Ilavarasu JV. Effect of yoga based techniques on stress and health indices using electro photonic imaging technique in managers. Journal of Ayurveda and Integrative Medicine. 2016;7(2):119-123. Available from: https://dx.doi.org/10.1016/j.jaim.2015.05.001.

12) Kushwah KK, Nagendra HR, Srinivasan TM. Effect of Integrated Yoga program on energy outcomes as a measure of preventive health care in healthy people. Central European Journal of Sport Sciences and Medicine. 2015;12(4):61-71. Available from: https://dx.doi.org/10.18276/cej.2015.4-07.

13) Bhat R, Mavathur R, Srinivasan TM. Diabetes mellitus type 2 and yoga: Electro photonic imaging perspective. International Journal of Yoga. 2017;10(3). Available from: https://dx.doi.org/10.4103/0973-6131.213469.

14) Hegde JR, Melukote SK, Vijayendra K, Singh D. A randomized study on the energy difference measured by electro photonic image on caregivers practiced Indian aesthetic dance and yoga. International Journal Of Community Medicine And Public Health. 2020;7(7). Available from: https://dx.doi.org/10.18203/ 
2394-6040.ijcmph20203013.

15) Yogananda P, Kriyananda S. Demystifying Patanjali - The Yoga Sutras (Aphorisms). Nevada: Crystal Clarity. 2013.

16) Lee YS, Ryu Y, Jung WM, Kim J, Lee T, Chae Y. Understanding mind-body interaction from the perspective of east Asian medicine. 2017. Available from: https://doi.org/10.1155/2017/7618419.

17) Hankey A. CAM and the Phenomenology of Pain. Evidence-Based Complementary and Alternative Medicine. 2006;3(1):139-141. Available from: https://dx.doi.org/10.1093/ecam/nek002.

18) Bhatta CP. Holistic Personality Development through Education. Journal of Human Values. 2009;15(1):49-59. Available from: https://dx.doi.org/10.1177/ 097168580901500104.

19) Brems C, Freeman H, Vladagina N, Razmjou E. Yoga in print media: Missing the heart of the practice. International Journal of Yoga. 2017;10(3). Available from: https://dx.doi.org/10.4103/ijoy.ijoy_1_17.

20) Korotkov K, Williams B, Wisneski LA. Assessing Biophysical Energy Transfer Mechanisms in Living Systems: The Basis of Life Processes. The Journal of Alternative and Complementary Medicine. 2004;10(1):49-57. Available from: https://dx.doi.org/10.1089/107555304322848959.

21) Korotkov KG. The Energy of Health: Understanding Bio-Well Analysis. Create Space Independent Publishing Platform. 2017.

22) Schure MB, Christopher J, Christopher S. Mind-Body Medicine and the Art of Self-Care: Teaching Mindfulness to Counseling Students Through Yoga, Meditation, and Qigong. Journal of Counseling \& Development. 2008;86(1):47-56. Available from: https://dx.doi.org/10.1002/j.1556-6678.2008.tb00625.x.

23) Gard T, Noggle JJ, Park CL, Vago DR, Wilson A. Potential self-regulatory mechanisms of yoga for psychological health. Frontiers in Human Neuroscience. 2014;8:1-20. Available from: https://dx.doi.org/10.3389/fnhum.2014.00770.

24) Roche LT, Barrachina MTM, Fernández II, Betancort M. YOGA and self-regulation in management of essential arterial hypertension and associated emotional symptomatology: A randomized controlled trial. Complementary Therapies in Clinical Practice. 2017;29:153-161. Available from: https: //dx.doi.org/10.1016/j.ctcp.2017.09.012.

25) Pascoe MC, Bauer IE. A systematic review of randomised control trials on the effects of yoga on stress measures and mood. Journal of Psychiatric Research. 2015;68:270-282. Available from: https://dx.doi.org/10.1016/j.jpsychires.2015.07.013.

26) Narayanan CR. EPI Reading of Before and After Yoga Session. . Available from: http://iumab.club/assets/files/papers/Yoga/2014\%20Rajan\% 20Narayanan_EPI_Yoga\%20Session\%20.PDF.

27) Hacker GW, Augner C, Pauser G. Daytime-related rhythmicity of GDV parameter glow image area: time course and comparison to biochemical parameters measured in saliva. . Available from: http://iumab.club/assets/files/papers/BioEnergy/2007Hacker.pdf.

28) Dale C. The Subtle Body: An Encyclopedia of Your Energetic Anatomy. Sounds True. 2009.

29) Damasio A, Carvalho GB. The nature of feelings: evolutionary and neurobiological origins. Nature Reviews Neuroscience. 2013;14(2):143-152. Available from: https://dx.doi.org/10.1038/nrn3403.

30) Nummenmaa L, Glerean E, Hari R, Hietanen JK. Bodily maps of emotions. Proceedings of the National Academy of Sciences. 2014;111(2):646-651. Available from: https://dx.doi.org/10.1073/pnas.1321664111. 